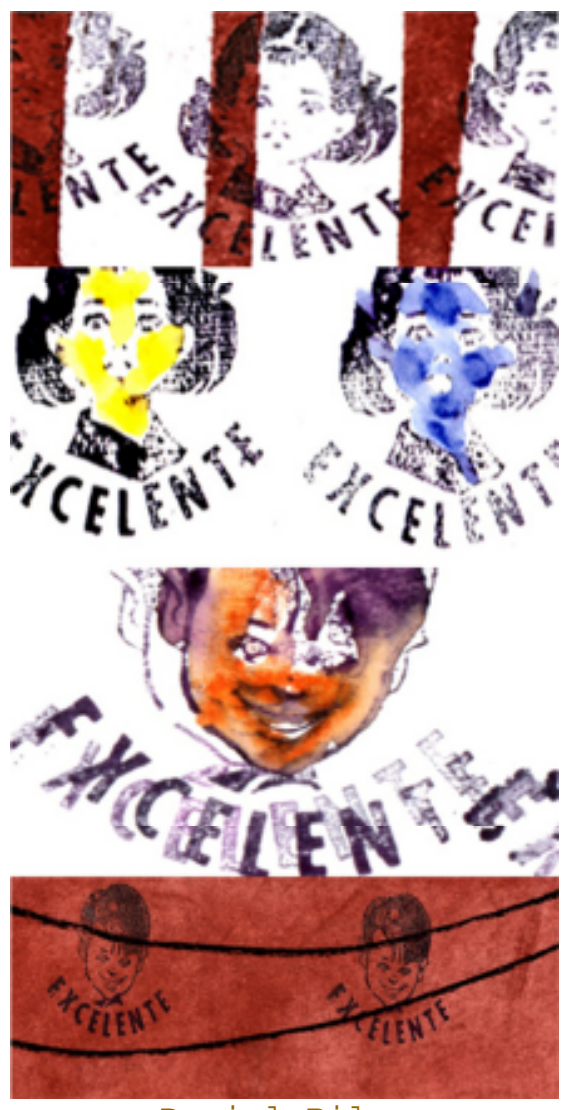

Daniel Bilac

\title{
A leitura nas narrativas docentes
}

\section{Santuza Amorim da Silva}

Doutora em Educação pela Universidade Federal de Minas Gerais/ Professora da Faculdade de Educação/UEMG e Coordenadora do NEPEL/FAE/UEMG (Núcleo de Estudos e Pesquisa em Educação e Linguagem).

\section{Resumo}

Serão tratadas, neste artigo, algumas experiências de leitura de um grupo de docentes, que fizeram parte de uma pesquisa mais ampla, realizada no Programa de Pós-graduação da FAE/UFMG. Um dos aspectos aqui tratados atém-se a analisar a predominância e a recorrência do aparecimento de determinados gêneros de leitura nos relatos concedidos pelas docentes. 
Palavras-chave: práticas leitoras, letramento docente, formação de leitores.

\section{Apresentação}

A pesquisa na qual este texto se inscreve teve como objetivo descrever e analisar as relações, as práticas e o processo de socialização de um grupo, constituído por quinze docentes, em relação à leitura. As informantes participaram de um projeto de formação continuada, realizado pela Universidade em pareceria com a SEE/MG e O MEC, com o propósito de alcançar a redefinição da formação de professores do ensino fundamental, no domínio da leitura e da escrita, no sentido de tornar o(a) professor(a) um(a) leitor(a), para que ele/ela pudesse atuar, de maneira competente, no cotidiano de sua prática docente.

Os dados foram adquiridos - por meio de entrevistas semiestruturadas, de esquema livre e de aplicação de questionários - permitindo o acesso aos relatos e à memória(1) desse grupo.

O interesse por tais práticas advém do fato de que, nos últimos anos, vimos se acentuar o debate em torno da formação docente e de suas práticas de leitura. Vários fóruns e pesquisas foram engendrados em torno dessa discussão. A temática tornou-se também alvo da mídia(2), quase sempre conferindo aos docentes a imagem de não-leitores ou de leitores precários, pouco familiarizados com a leitura. Além disso, outros dados conjunturais das condições de letramento da população brasileira confirmam a relevância de debruçar-se sobre as leituras docentes, visto que a escola se destaca como uma das principais agências de formação de leitores no país.

\section{Leitura: experiência e sentido na vida de professoras}

Tomaram-se, no contexto desta pesquisa, as práticas de leitura das professoras como manifestação de uma experiência/sentido. Em relação ao uso da palavra "experiência", Jorge Larrosa(3), pesquisador espanhol, vem utilizando-a, há algum tempo, como ferramenta para suas análises no campo pedagógico, principalmente nos estudos sobre a literatura e a experiência de leitura. O autor ressalta que a experiência tem sido entendida como um conhecimento inferior, sendo menosprezada e tratada como linguagem menor, no âmbito da filosofia e da ciência moderna. Segundo o autor, para a filosofia, a experiência é um obstáculo para o verdadeiro conhecimento, enquanto, para ele, a distinção platônica entre o mundo sensível e o inteligível equivale, em parte, à distinção entre doxa(opinião) e episteme(ciência). Para a ciência, a experiência é sempre subjetiva, contextual, finita, ligada à 
fugacidade do tempo, a situações concretas e particulares, impossível de ser objetivada e universalizada. Contudo, o autor desenvolve um raciocínio no sentido de reivindicar a experiência, em tudo aquilo que tanto a filosofia como a ciência desprezam: a subjetividade, a incerteza, o provisório, o corpo, a finitude, a vida.

O autor indica a necessidade de se tomar algumas precauções com relação ao uso do termo, no sentido de "limpar" a palavra de algumas contaminações que a fazem demasiadamente cômoda ou segura - a primeira delas seria a separação entre experiência e experimento - e de descontaminar a palavra das implicações empíricas e experimentais. A segunda precaução seria separar a experiência de todo dogmatismo e de toda pretensão de autoridade; a terceira, consistiria em separar experiência e prática; isso significa que o sujeito da experiência é um sujeito receptivo, aberto, disponível, exposto. Outra precaução, de acordo com Larrosa, tratar-se-ia de fazer da experiência um conceito. Ele explica que tem feito um esforço para vincular a experiência à palavra existência, isto é, a um modo de habitar o mundo. Dessa maneira, a existência, como a vida, não poderia ser conceitualizada, pois sempre escapa a qualquer determinação e traz em si a possibilidade de criação, de invenção e de acontecimento. Por fim, o autor recomenda o cuidado para não converter a palavra experiência em um fetiche - no sentido de torná-la um imperativo e de utilizá-la de forma precisa - assim evitando que qualquer coisa se converta em experiência.

Enfim, para Larrosa(4), "a experiência é o que nos passa, o que nos acontece, o que nos toca". É ela que forma, constitui personalidades e identidades. Desse modo, 0 sujeito da formação não é o sujeito da aprendizagem, mas o sujeito da experiência, embora o autor admita que exista uma relação clássica entre essas duas instâncias. Interessa-nos, sobremaneira, esse viés da experiência. Sendo assim, pretendese aqui refletir sobre as práticas de leitura das professoras, com base, sobretudo, nos relatos das experiências vividas por elas, em diferentes situações, no intuito de desvelar aquilo que as tocou.

Os dados colhidos revelaram que, no grupo investigado, para as professoras cujo contato com a leitura mostrou-se frágil, no seio familiar e na escola, houve, na idade adulta, uma intensificação dessa prática de forma mais significativa. Avaliaram que convivem mais com a leitura hoje. Mencionaram ler, atualmente, alguns autores da área da Educação como Içami Tiba, Paulo Freire, e também Rubem Alves. Além disso, destacaram as fábulas, os livros de auto-ajuda e os livros que gravitam em torno de questões referentes ao racismo, aos valores, à ética e à disciplina - justificam tais escolhas em 
função dos problemas de violência e preconceitos enfrentados no cotidiano de suas escolas.

Identificou-se em outro grupo que, mesmo tendo vivido oportunidades interessantes na infância ou na adolescência, afirmaram que o contato com as práticas de leitura se efetiva de forma mais substancial no momento atual, por motivos profissionais. Vejamos o caso da professora Marta: "acho que leio muito mais agora (...) desvairadamente (...) estou tentando recuperar o tempo perdido". Isso porque, segundo ela, quando trabalhava "como professora de português - sabe, aquela que só corrige? - então, eu tinha muito livro que guardei para quando aposentasse". Em suas leituras cotidianas e de lazer, ela costuma ler romances, biografias e faz referência a vários livros e autores desses gêneros, como Érico Veríssimo, Clarice Lispector, Pedro Nava, Zélia Gatai, dentre outros. Ela ainda menciona que, para subsidiar a sua prática profissional(5), procura ler e reler alguns clássicos, e obras que fazem parte do repertório da literatura infantil em geral: Monteiro Lobato, Cecília Meireles e outros.

Marta procura buscar uma literatura que trate das questões da existência humana e, nessa direção, destaca a literatura espirita. Além disso, define-se como uma leitora eclética, que gosta de ler vários gêneros e textos, desde que a satisfaçam: "embora eu não seja espírita, adoro a literatura. Não sei se acredito em tudo (...) porque sou o tipo de leitora que quer ler tudo o que existe, tudo que encontra."

Outro grupo de professoras - Silvana, Cláudia, Maria Rosa, Luma e Ângela - reconhece que esse é o momento em que as práticas de leitura se fazem mais presentes em suas vidas. A maioria delas realiza suas leituras com o intento de suprir as demandas decorrentes da vida cotidiana: solucionar problemas domésticos, lacunas na formação profissional, subsidiar o fazer docente e ainda por motivos espirituais e religiosos. Não obstante, há uma característica comum entre elas: consideram-se "leitoras fracas", não reconhecem as leituras efetivadas como práticas legítimas(6).

Algumas afirmaram que procuram ler a respeito dos problemas relacionados à fase da adolescência, objetivando acompanhar e compreender melhor os filhos, que se encontram nessa faixa etária. As preferências apontadas por esse grupo são os livros de abordagem kardecista e, nesse aspecto, destacou-se Zíbia Gasparetto, autora reconhecida nesse âmbito. Outras leituras que compõem o repertório atual da maioria das docentes são a literatura infantil e as revistas em quadrinhos, objetivando seu uso na prática docente. 
No conjunto das entrevistadas, somente uma professora, Meiriane, assume que a leitura se fez presente em toda a sua trajetória de socialização - nos contextos familiar, escolar e de formação. Ela acentua que: "a leitura nunca saiu da minha vida... eu não tinha percebido que, desde que me alfabetizei, estava sempre com algum manual ou livro de receitas (...); mais tarde, romances. Eu estava sempre lendo alguma coisa em seqüência: quando acabava um, começava outro".

Semelhantemente a outras colegas, ela cultiva o hábito de ler literatura espírita, "de maneira um pouco exacerbada", preferencialmente, os livros de André Luiz e Zíbia Gasparetto. Não obstante, parece refletir um pouco e tenta se justificar, concluindo: "estou em um momento crítico (...), questionando a doutrina".

\section{Tecendo considerações}

Um aspecto relevante a ser considerado é que despontaram nos relatos alguns autores ou obras que têm como finalidade subsidiar as professoras nas soluções de problemas emergentes em sua prática docente. Observa-se um elenco de obras afetas a conteúdos, como a literatura infanto-juvenil, ou a referência a autores cujas temáticas giram em torno de problemáticas da disciplina escolar. Essa particularidade, detectada nas leituras docentes, faz com que esse grupo possa ser caracterizado como leitores ordinários, no sentido de que há uma tendência, por parte dele, de estabelecer uma relação pragmática com os objetos lidos.

Além disso, detectou-se que elas tendem a eleger como objeto de leitura a literatura de auto-ajuda(7). Foram vários os motivos que justificam tal escolha, desde a solução para os problemas da vida profissional e cotidiana até a questão religiosa. Constatou-se a presença desse tipo de literatura em 80\% dos depoimentos, confirmando 0 que a mídia(8) vem reportando sobre esse fenômeno, no contexto da indústria cultural. A elevada procura desse gênero, entre as professoras do grupo, parece assemelhar-se a outros dados já detectados por pesquisas(9) que apontam a tendência de um acentuado gosto do(a) professor(a) pela literatura colocada em circulação pela cultura de massa.

Analisando os depoimentos, não nos pareceu que, em sua maioria, elas estivessem preocupadas em responder àquilo que é mais apropriado em relação aos objetos de leitura que merecem ser declarados, embora muitas se reconheçam como "leitoras fracas". Apesar de essa literatura ser considerada, por parte dos intelectuais e da academia, como cultura menor, sem valor, e cultivada por pessoas com repertório intelectual inferior, 
suas respostas não demonstraram uma tendência em negar a leitura desse gênero. Não nos pareceu também que elas estariam aqui preocupadas em passar uma imagem de "bom leitor", isto é, daquele que tem acesso à literatura considerada "legítima".

Esse dado torna-se significativo se tomarmos as reflexões de Abreu :

\begin{abstract}
- cânone universal dos textos escritos, capaz de assegurar a disseminação dos valores culturais, políticos e religiosos, nos quais se ancora a visão de mundo das elites, parece ameaçado (...) - repúdio ou o estímulo à leitura só podem ser bem compreendidos se forem examinados os objetos que se tomam para ler e sua relação com questões políticas, estéticas, morais, religiosas nos diferentes tempos e lugares.(10)
\end{abstract}

E, mais ainda, as recentes considerações oriundas do campo da sociologia da leitura podem clarear pontos obscuros desse fenômeno cultural detectado nas declarações. Estudos como o de Horellou-Lafarge et Segré(11)apontam que a conhecida tendência dos interrogados responderem, sobre suas leituras, com certa precaução e em conformidade com as normas culturais legítimas, subestimando suas escolhas pessoais, foi alterada nos últimos trinta anos. O estudo sinaliza que houve interiorização de um fenômeno, o qual os pesquisadores denominam "banalização da leitura e do livro", por parte de determinados segmentos sociais, o que faz com que suas declarações se aproximem cada vez mais das práticas efetivas e reais.

Nessa mesma linha de raciocínio, podemos inferir que a insistente incidência da literatura de auto-ajuda nos depoimentos permite indagar sobre a relação entre o tempo, o lugar e as novas práticas que se impõem, isto é, as novas maneiras de ler e os novos objetos de leitura(12). Assim, a modernidade apresentaria desafios e imporia nova lógica de comportamento, em que se estabelecem novos valores, uma vez que ela se caracteriza por uma sociedade consumista, pelo culto ao descartável, pela rapidez e pelo individualismo. Na sociedade cada vez mais narcisista e consumista da pósmodernidade, a literatura de auto-ajuda é (13) uma maneira de auxiliar o leitor na busca da compreensão de si e do universo social que o cerca.

\title{
Abstract
}

In this article, some experiences accomplished by a group of teachers on reading are shown. These experiences were part of a broader research during a Postgraduate Program at FAE/UFMG. One of the aspects studied here aims at analyzing the predominance and repetition of certain reading genres on the teachers' reports.

Key-words: reading practices, teachers literacy, readers formation. 


\section{Notas}

[1] recurso à memória, para a reconstituição de processos de formação docente já é recorrente no Brasil, desde 1997, tanto para os estudos histórico-educacionais quanto para aqueles que tratam da pesquisa acerca da formação docente. Cf. Catani, 1997.

[2] A análise de textos veiculados pela imprensa, nos últimos anos, constata que a imagem retratada dos docentes é a de um(a) professor(a) que é incapaz de escrever, que não tem o hábito de leitura e que, conseqüentemente, estaria formando poucos leitores. Cf. Guedes-Pinto, 2002.

[3] O ator apresenta essa linha de pensamento em diferentes obras: Larrosa $(1996,2002)$.

[4] LARROSA, 2002, p. 21 .

[5] A referida professora, após a aposentadoria no ensino médio, reinicia as atividades docentes no ensino superior, na área de formação de professores (as).

[6]A discussão sobre a concepção do termo "legítimo" encontra-se no trabalho de pesquisa mais amplo no qual este artigo se inscreve. Tomaram-se como referencial de análise as formulações do sociólogo Pierre Bourdieu. Ver SILVA (2007).

[7]Esses livros assumem uma variedade de formas, dificultando a categorização do gênero. Porém, conforme Asbahr, é possível afirmar que os livros de auto-ajuda se dividem entre aqueles que abordam questões objetivas e subjetivas, apresentando um discurso prescritivo e aconselhador. Os temas são diversificados e tratam de dificuldades enfrentadas no cotidiano, propondo soluções para problemas profissionais ou de saúde, como lidar com filhos únicos, superar medos, conquistar o(a) parceiro(a) desejado (a).

[8] A revista Época, n. 261, de maio de 2003, traz dados que revelam o crescimento desse gênero no mercado editorial brasileiro. De acordo com a matéria, Zibia Gasparetto, uma das autoras desse ramo, que se dedica a produzir livros espíritas, esotéricos e de auto-ajuda, vendeu mais de 5 milhões de livros desde 1995. Observa-se que esse dado foi referendado nos depoimentos das docentes, quando essa autora aparece em suas listas de predileções.

[9]BAtIstA, Pesquisa Nacional sobre o perfil dos professores brasileiros (Inep/Unesco, 2004).

[10] BATISTA, 1999. p.15.

[11] HORELLOU-LAFARGE， 2003.

[12]Chartier (2001) e Ariès (1991) revelam que as alterações sofridas nas práticas individuais e sociais de leitura variam em decorrência do tempo e espaço: da leitura oral e coletiva para a leitura silenciosa e individual, das práticas extensivas às praticas intensivas.

[13] Embora sem o intuito de alongar essa discussão, as reflexões aqui elaboradas tomaram por base as formulações de Japiassu sobre a crise da modernidade. Para ele, estamos sob os auspícios da pós-modernidade e esta se caracterizaria pela imposição de um estilo de pensamento marcado pela 
desconfiança da Razão, o que levaria o ser humano a incertezas, ao desencantamento, à apatia, ao ceticismo e a indiferença. Japiassu acrescenta ainda que, no plano do Absoluto, o Deus do homem atual é uma divindade que se encontra além das representações e conceitos, confundindose, na prática, com uma espécie de conhecimento esotérico, místico, transcendental, oculto ou religioso (auto-conhecimento). Cf. JAPIASSU, H. A crise da razão no ocidente. Revista Eletrônica Sinergia. Disponível em: http://www.sinergia.spe Acesso em: 15 nov. 2006.

\section{Bibliografia}

ABREU, Márcia. Percursos da leitura. In: (org.). Leitura, história e história da leitura. Campinas: Mercado de Letras, 1999. p. 9-18.

ARIÈs, P. As práticas da escrita. In: História da vida privada. São Paulo: Companhia das Letras, 1991.

ASBAHR, Melissa C. Os professores leitores dos livros de auto-ajuda para crianças. São Paulo: UNICAMP, 2005. (Dissertação de Mestrado).

BATISTA, A. A. Um objeto variável e instável: textos, impressos e livros didáticos. In: ABREU, Márcia (org.). Leitura, história e história da leitura. Campinas: Mercado de Letras, 1999.

CATANI, Denise (org.). Docência, memória e gênero: estudos sobre a formação. São Paulo: Escrituras, 1997.

CHARTIER, Anne-Marie. Fazeres ordinários da classe: uma aposta para a pesquisa e para a formação. Educação e Pesquisa, v. 26, jul./dez. 2000.

CHARTIER, R. Cultura escrita: literatura e história. Porto Alegre: Artmed, 2001 .

GUEDES PINTO, Ana Lúcia. Rememorando trajetórias da professoraalfabetizadora. Campinas: Mercado de Letras, 2002.

HORELLOU-LAFARGE, C.; SEgRÉ, M. Sociologie da la lecture. Paris: La Découverte, 2003.

INEP. O perfil dos professores brasileiros: o que fazem, o que pensam e o que almejam. São Paulo: Moderna, 2004 .

JAPIASSU, H. A crise da razão no ocidente. Revista Eletrônica Sinergia. Disponível em: http://www.sinergia.spe. Acesso em: 15 nov. 2006.

LARROSA, Jorge. La experiencia de la lectura. In:Estudios sobre lectura y formación. Barcelona: Laertes, 1996.

- Notas sobre a experiência e o saber da experiência.Revista Brasileira de Educação. Campinas, n.19, p. 20-28, 2002.

SILVA, Santuza Amorim da. Leitura e práticas de formação docente: o caso do Pró-Leitura. Belo Horizonte: FAE/UFMG, 2007. (Tese de Doutorado). 